\title{
Hearing Outcome in Stapes Surgery Using Various Biomaterial Prostheses
}

\author{
Sasindran Vivek, N. K. Febin, Mathew Nidhi, B. Harikrishan \\ Department of Otorhinolaryngology and Head \& Neck Surgery, Pushpagiri Medical College, Tiruvalla, India \\ Email: viveksasindran@hotmail.com
}

How to cite this paper: Vivek, S., Febin, N.K., Nidhi, M. and Harikrishan, B. (2018) Hearing Outcome in Stapes Surgery Using Various Biomaterial Prostheses. International Journal of Otolaryngology and Head \& Neck Surgery, 7, 330-343. https://doi.org/10.4236/ijohns.2018.76033

Received: August 10, 2018

Accepted: November 6, 2018

Published: November 9, 2018

Copyright ( 92018 by authors and Scientific Research Publishing Inc. This work is licensed under the Creative Commons Attribution International License (CC BY 4.0).

http://creativecommons.org/licenses/by/4.0/ (c) (i) Open Access

\begin{abstract}
Aims: To assess the hearing outcome in patients who have undergone stapes surgery using polytetrafluoroethylene (PTFE) and Titanium prosthesis at 1 and 3 months post operatively. Material \& Methods: Research design: Prospective study. Setting: ENT department, Pushpagiri Medical College. Study population: All age groups with clinical diagnosis of otosclerosis and air-bone gap more than $15 \mathrm{~dB}$ irrespective of sex difference. Patients with Meniere's disease are excluded. Method: A prospective study was conducted for a period of one and a half years from January 2014 to July 2015 to find out the hearing outcome of stapes surgery in patients with otosclerosis using polytetrafluoroethylene (PTFE) and Titanium prostheses, attending our outpatient department. Results: In this study, $84.21 \%$ of ears with polytetrafluoroethylene (PTFE) and $81.81 \%$ of ears with titanium were able to achieve good results in terms of Air-Bone gap (ABG) closure (ABG $<20 \mathrm{~dB}$ ). The average post op hearing following stapes surgery at 3 months improved to near normal levels of $34.12 \mathrm{~dB} \pm 8.95$ with an average hearing gain of $19.19 \mathrm{~dB}$ with PTFE prosthesis and $30.86 \mathrm{~dB} \pm 5.47$ with an average hearing gain of $21.2 \mathrm{~dB}$ with titanium which were significant. Conclusion: Stapes surgery is the surgical procedure of choice for otosclerosis. In our study, a significant hearing improvement was seen in majority of cases. None of the factors considered relevant for the success of stapes surgery like age, sex, type of prosthesis appeared to affect the post-operative hearing significantly. Hence stapes surgery can be effectively used to improve hearing in otosclerosis.
\end{abstract}

\section{Keywords}

Otosclerosis, PTFE and Titanium, AC Threshold Gain, AB Gap

\section{Introduction}

Otosclerosis is the most common cause of progressive conductive hearing loss in 
adults. It is more common in females with 2:1 female to male ratio. The age of onset is usually third decade of life. The hearing loss is bilateral in $70 \%$ of cases. Otosclerosis is transmitted in an autosomal-dominant fashion with variable penetrance.

Otosclerosis is a localized hereditary disorder affecting endochondral bone of the otic capsule that is characterized by disordered resorption and deposition of bone. It begins as spongification of the bone of the otic capsule. It may cause conductive hearing loss, a mixed hearing loss or occasionally a purely sensorineural hearing loss.

In 1860, Toynbee [1] first described the condition causing a hearing loss by fixation of the stapes. In 1893, Politzer [2] referred to the fixation of the stapes asotosclerosis. Siebenmann [3] revealed on microscopic examination that the lesion seemed to begin as spongification of the bone and termed the process otospongiosis.

The main complaint of the patient will be progressive hearing loss. If it involves stapes, hearing loss will be conductive; the commonest site of involvement being anterior crura. The disease progresses to involve the entire footplate. It may progress anteriorly to involve the cochlea leading to sensorineural hearing loss as shown in Figure 1.

Otosclerosis is an autosomal dominant disease with variable penetrance and expression. Women are more affected (2:1). Age of onset is late teens or early 20 s, but may not occur until the 30s or early 40s. At the House Ear Clinic, the youngest patient with surgically confirmed otosclerosis was 6 years old [4]. It is aggravated in pregnancy and many present with symptoms after their first pregnancy. Clinicalotosclerosis is rare in blacks, Asians, and Native Americans [5]-[11].

Occasionally, the lesion may involve only the cochlea, causing an isolated sensorineural hearing loss. Sometimes the entire cochlea is surrounded by otosclerosis, causing total deafness. In the United States, 20 of the first 57 patients to have a cochlear implant were made deaf by otosclerosis [12].

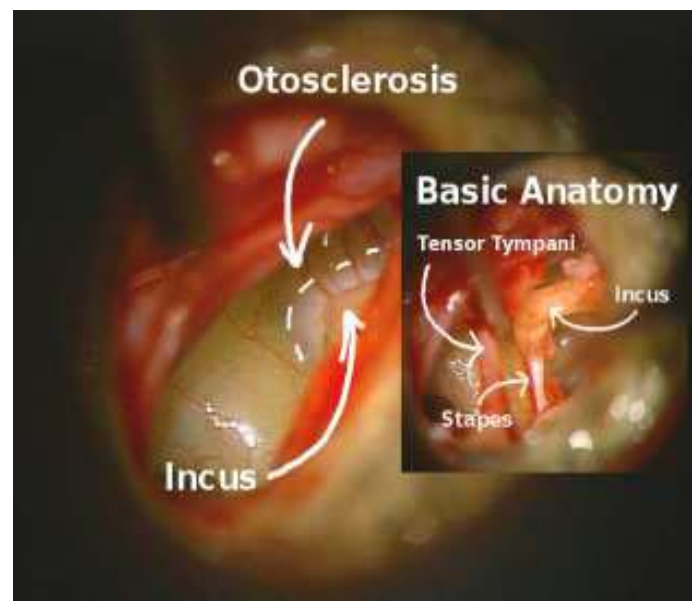

Figure 1. Otosclerosis basic anatomy [13]. 


\section{Methods}

\subsection{Type of Study and Source of Data}

A prospective study was conducted for a period of one and a half years from January 2014 to July 2015 to find out the hearing outcome of stapes surgery in patients with otosclerosis using PTFE and Titanium prostheses, attending ENT OPD at Pushpagiri Institute of Medical Sciences and Research Centre, Thiruvalla, Kerala.

\subsection{Inclusion Criteria}

Patients presenting with history, clinical features and audiological findings of otosclerosis with air-bone gap of more than $15 \mathrm{~dB}$ with conductive hearing loss andintact tympanic membrane who underwent stapes surgery with various biomaterial prostheses. Patients of both sex, all age groups, patients who underwent bilateral and revision surgeries come under the study.

\subsection{Exclusion Criteria}

Patients with Meniere's disease are excluded from the study.

\subsection{Method of Data Collection}

All patients with clinical diagnosis of otosclerosis with air-bone gap of more than $15 \mathrm{~dB}$ across $500 \mathrm{~Hz}, 1000 \mathrm{~Hz}$, and $2000 \mathrm{~Hz}$ in whom stapes surgery was planned and were willing to undergo surgery were selected for surgery. A total of 30 ears (28 patients where two patients underwent bilateral surgery) had undergone stapes surgery during the study period. A complete history, ENT examination and appropriate investigations [Pure Tone Audiogram, Speech Audiometry, Tympanometry] were done to arrive at the correct diagnosis.

\section{Results}

A total of 30 ears (28 patients where two patients underwent bilateral surgery) of otosclerosis underwent stapes surgery with either polytetrafluroethylene (PTFE) or Titanium in Pushpagiri Medical College from January 2014 to July 2015. All the patients were available for PTA follow up at 1 month and 3 months after surgery and they were compared with pre operative PTA value. All the cases were operated by a single surgeon. The data were analyzed under the following headings:

1) Patient factors;

2) Surgical factors;

3) Results.

\subsection{Patient Factors}

\subsubsection{Age Distribution (Number of Patients)}

Out of the, $53.57 \%$ of the patients were between the age group of 21 to 40 years. There was only one patient above 70 years. 


\subsubsection{Sex Distribution (Number of Patients)}

In our series of 28 patients ( 30 ears since two patients underwent bilateral surgery), 14 were males and 14 were females. The male to female ratio was 1:1.

\subsection{Surgical Factors}

\section{Type of Prosthesis (Number of Ears Operated)}

Out of 30 ears (28 patients where two patients underwent bilateral surgery), 19ears underwent stapes surgery with PTFE biomaterial prosthesis, 11 underwent surgery with titanium prosthesis.

Table 1 shows, out of 28 patients ( 30 ears since two patients underwent bilateral surgery), 2 patients underwent bilateral stapes surgery and 26 patients underwent unilateral surgery. So there were $7.17 \%$ patients of bilateral and $92.86 \%$ patients of unilateral stapes surgery.

Table 2 shows, one patient had to undergo revision surgery out of 28 patients (30 ears since two patients underwent bilateral surgery). It was due to dislocation of prosthesis and was operated second time 3 months after primary surgery.

\subsection{Results}

TITANIUM: The average pre-op hearing loss was (AC) was $52.06 \mathrm{~dB} \pm 7.70$. The average post op hearing (AC) at 1 month follow up was $39.33 \mathrm{~dB} \pm 6.85$ with an average hearing gain of $12.73 \mathrm{~dB}$ which was significant. The average post op hearing $(\mathrm{AC})$ at 3 months improved to $30.86 \mathrm{~dB} \pm 5.47$ with an average hearing gain of $21.2 \mathrm{~dB}$ which was also significant as shown in Figure 2 .

PTFE: The average pre-op hearing loss was $(\mathrm{AC})$ was $53.31 \mathrm{~dB} \pm 7.71$. The average post op hearing (AC) at 1month follow up was $41.75 \mathrm{~dB} \pm 7.53$ with an average hearing gain of $11.56 \mathrm{~dB}$ which was significant. The average post op hearing ( $\mathrm{AC}$ ) at 3 months improved to $34.12 \mathrm{~dB} \pm 8.95$ with an average hearing gain of $19.19 \mathrm{~dB}$ which was also significant as shown in Figure 2.

TITANIUM: -In our study of 30 ears operated (28 patients where two patients underwent bilateral surgery), based on improvement of $A B$ gap (according to Wehr's classification), 8 ears had excellent improvement at 3 months post operatively, 1 ear had good improvement, 2 ears fair improvement and no failure cases by the end of 3 months post op as shown in Figure 3 .

PTFE: -In our study, 12 ears had excellent improvement at 3 months post operatively, 4 ears had good improvement, 1 ear fair improvement and 2 failure cases by the end of 3 months post op as shown in Figure 3 .

TITANIUM: -The average pre op ABG was $28.67 \mathrm{~dB} \pm 4.60$. The average post op $A B G$ at 1 month post op follow up was $17.21 \mathrm{~dB} \pm 7.37$ with an average closure of $11.46 \mathrm{~dB}$ which was found to be significant. The average post op ABG at 3 months post op follow up was $12.36 \mathrm{~dB} \pm 5.29$ with an average closure of 16.31 $\mathrm{dB}$ which was found to be significant as shown in Figure 4.

PTFE: -The average pre op ABG for PTFE prosthesis was $29.26 \mathrm{~dB} \pm 8.73$. The average post op ABG at 1 month post op follow up was $18.26 \mathrm{~dB} \pm 7.14$ with an average closure of $11 \mathrm{~dB}$ which was found to be significant. The average post op 
$\mathrm{ABG}$ at 3 months post op follow up was $14.2 \mathrm{~dB} \pm 8.62$ with an average closure of $15.06 \mathrm{~dB}$ which was found to be significant as shown in Figure 4 .

Table 3 shows the average AC threshold post op at 1 month using PTFE was $41.75 \pm 7.53$. The average AC threshold post op at 1 month using titanium was $39.33 \pm 6.85$. The comparative study was not statistically significant. The average AC threshold post op at 3 months using PTFE was 34.12 \pm 8.95 . The average AC threshold post op at 3 months using titanium was $30.86 \pm 5.47$. The comparative study was not statistically significant.

The average ABG threshold post op at 1 month using PTFE was 18.26 \pm 7.14. The average ABG threshold post op at 1 month using titanium was 17.21 7.37. The comparable study was not statistically significant.

The average ABG threshold post op at 3 month using PTFE was $14.2 \pm 8.62$. The average ABG threshold post op at 3 month using titanium was $12.36 \pm 5.29$. The comparative study was not statistically significant as shown in Table 4.

84.21\% ears with PTFE has good to excellent improvement (less than $20 \mathrm{~dB}$ ) in ABG at 3 months post operatively. $81.81 \%$ ears with titanium has good to excellent improvement (less than $20 \mathrm{~dB}$ ) in ABG at 3 months post operatively as described in Table 5 .

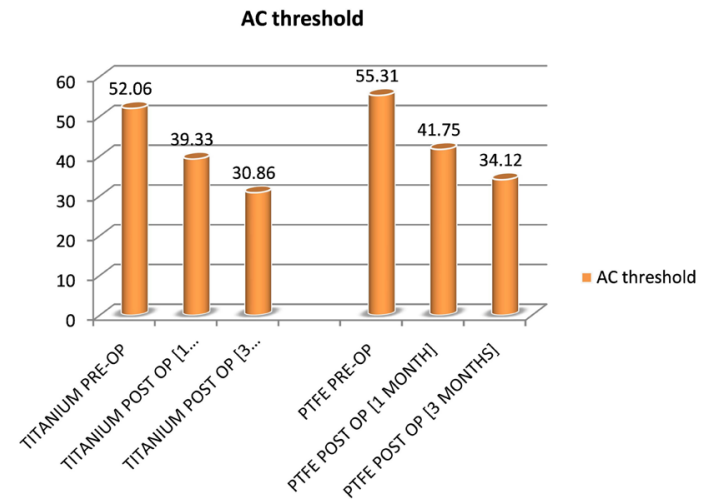

Figure 2. Improvement in terms of difference between pre and post op AC threshold with Titanium and PTFE Prosthesis.

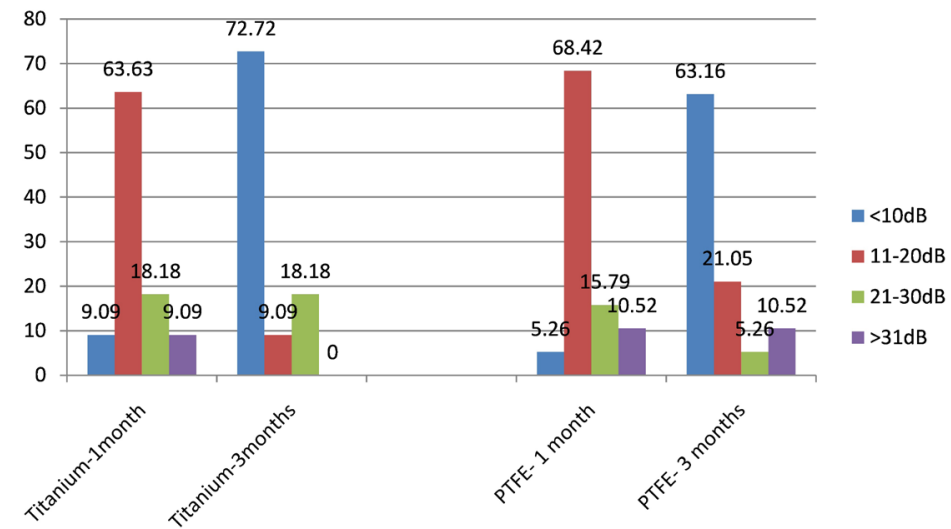

Figure 3. ABG results in number of ears operated at 1 and 3 months post op with Titanium prosthesis and PTFE prosthesis (Wehr's classification). 


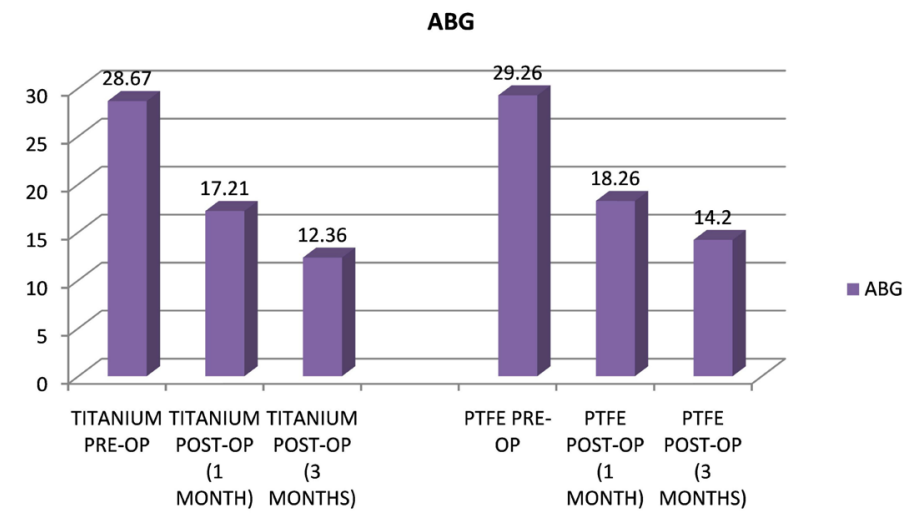

Figure 4. Improvement in terms of difference between pre-op and post op $\mathrm{ABG}$ and $\mathrm{ABG}$ closure with Titanium prosthesis and PTFE prosthesis.

Table 1. Number of unilateral and bilateral cases (number of patients).

\begin{tabular}{ccc}
\hline Total no. of patients operated & Number & Percentage \\
\hline Bilateral & 2 & 7.17 \\
Unilateral & 26 & 92.86 \\
Total & 28 & 100 \\
\hline
\end{tabular}

Table 2. Revision cases (number of ears operated).

\begin{tabular}{ccc}
\hline Total No. of ears operated & No. of revision cases & Percentage of revision cases \\
\hline 30 & 1 & 3.33 \\
\hline
\end{tabular}

Table 3. Comparison of AC threshold post op 1 month \& 3 months between PTFE and Titanium.

\begin{tabular}{|c|c|c|c|c|c|c|}
\hline \multicolumn{7}{|c|}{ Post-Op 1 month } \\
\hline \multicolumn{4}{|c|}{ PTFE } & \multicolumn{3}{|c|}{ Titanium } \\
\hline & Mean $(\mathrm{dB})$ & SD & P-value & Mean $(\mathrm{dB})$ & SD & P-value \\
\hline $\mathrm{AC}$ & 41.75 & 7.53 & 0.603 & 39.33 & 6.85 & 0.595 \\
\hline \multicolumn{7}{|c|}{ Post-Op 3 month } \\
\hline \multicolumn{4}{|c|}{ PTFE } & \multicolumn{3}{|c|}{ Titanium } \\
\hline & Mean $(\mathrm{dB})$ & SD & $\mathrm{p}$-value & Mean $(\mathrm{dB})$ & SD & $\mathrm{p}$-value \\
\hline $\mathrm{AC}$ & 34.12 & 8.95 & 0.385 & 30.86 & 5.47 & 0.326 \\
\hline
\end{tabular}

Table 4. Comparison of ABG post op 1 month \& 3 months between PTFE and Titanium.

\begin{tabular}{|c|c|c|c|c|c|c|}
\hline \multicolumn{7}{|c|}{ Post -op 1 month } \\
\hline \multicolumn{4}{|c|}{ PTFE } & \multicolumn{3}{|c|}{ Titanium } \\
\hline & Mean (dB) & SD & p-value & Mean $(\mathrm{dB})$ & SD & p-value \\
\hline $\mathrm{AC}$ & 18.26 & 7.14 & 0.662 & 17.21 & 7.37 & 0.666 \\
\hline \multicolumn{7}{|c|}{ Post-op 3 month } \\
\hline \multicolumn{4}{|c|}{ PTFE } & \multicolumn{3}{|c|}{ Titanium } \\
\hline & Mean (dB) & SD & p-value & Mean (dB) & SD & p-value \\
\hline $\mathrm{AC}$ & 14.2 & 8.62 & 0.652 & 12.36 & 5.29 & 0.609 \\
\hline
\end{tabular}


Table 5. Comparison of percentage of ears showing ABG post op betweenPTFE and Titanium prosthesis.

\begin{tabular}{ccccc}
\hline ABG & \multicolumn{2}{c}{ 1 month } & \multicolumn{2}{c}{ 3 months } \\
\hline & PTFE (\%) & Titanium (\%) & PTFE (\%) & Titanium (\%) \\
\hline$<$ 10 (excellent) & 5.26 & 9.09 & 63.16 & 72.72 \\
11 - 20 (good) & 68.42 & 63.63 & 21.05 & 9.09 \\
21 - 30 (fair) & 15.79 & 18.18 & 5.26 & 18.18 \\
$>$ 31 (failure) & 10.52 & 9.09 & 10.52 & 0 \\
\hline
\end{tabular}

\section{Discussion}

In the present study, 30 ears (28 patients where two patients underwent bilateral surgery) with otosclerosis underwent stapes surgery and were analyzed and followed up for post op improvement in hearing at 1 month and 3 months. Varioushost and surgical factors which could affect the surgical results were considered and analyzed.

The minimum age in our study group was 23 years and maximum age in the group was 73 years. The maximum number of patients was in the age group of 21 - 40 years (53.57\%). Clinical otosclerosis is more frequent between the ages of 20 and 30 (Nager, 1969) [14]. Some cases become evident as early as six or seven, but the majority manifest between ages 15 and 35, with a few cases as late as 54 years old (Shambaugh, 1961). Average ageof onset has been reported to be 33 (Panama, 1987), 29 (Minnesota, 1978), 24 (Chile, 1987), and 23 (Brazil, 1987).

Age does not significantly affect the success rate of stapes surgery. Kulakova et al. [15] found that the surgical intervention on the stirrup bone for the treatment of otosclerosis in the patients above 65 years of age is a safe and efficacious method despite marked hearing impairment in this group of patients. Massey et al. [16] evaluated the outcomes of stapedectomy surgery for congenital stapes fixation and found that stapedectomy remains an effective method to achieve significant hearing improvement in the majority of patients for congenital fixation. Age is not a detriment to hearing gain and instead might result in better use of hearing aids in older adults, thus facilitating social hearing recovery [17]. In our study group, there was no patient in paediatric age group and there is one patient in geriatric age group. Therefore, it is not possible to correlate age as a significant success factor for surgery.

Univariate and multivariate analyses indicated that none of the pre-operative factors (piston type, age, sex, affected side, tinnitus, vertigo, and pre-operative hearing thresholds) affected hearing success significantly (all $\mathrm{p}>0.05$ ).

In our series of 28 patients (30 ears since two patients underwent bilateral surgery), 14 patients were males and 14 were females. The male to female ratio was 1:1. The success of stapes surgery for otosclerosis is not dependent on sex of the patients [17]. The prevalence of otosclerosis is greater in women, with a 2:1 female-tomaledistribution [18]. The difference in the study arises due to random assignment. 
Shabana et al. [19] conducted study using a $0.4-\mathrm{mm}$ diameter Teflon platinumpiston and a $0.6-\mathrm{mm}$ diameter PTFE piston. The postoperative air-bone gap, calculated as the difference between the postoperative air and bone conduction levels, was smaller in the $0.6 \mathrm{~mm}$ group for all frequencies except at 2000 $\mathrm{Hz}$; the differences were statistically insignificant except at $4000 \mathrm{~Hz}$. It was concluded that the $0.4 \mathrm{~mm}$ and the $0.6 \mathrm{~mm}$ PTFE prostheses produced the same hearing improvement in stapessurgery for otosclerosis. In our series of study, we used diameters of $0.4 \mathrm{~mm}$ PTFE prosthesis and $0.4 \mathrm{~mm}$ titanium prosthesis. There was no significant difference in the hearing outcome. The measurement of the piston is always described as a significant stage of the surgery, but its length is never clearly defined [20].

The measurement of the length of the piston is very significant, and in our study, the majority of the pistons were cut at $4.75 \mathrm{~mm}$ which indicates an incus-footplate measurement of $4.25 \mathrm{~mm}$. In our series of cases, we routinely measured the length of the pistons which were $4.25-4.75 \mathrm{~mm}$ long. In our series of study, the fenestra was sealed with gel foam.

In this study, the hearing improvement at 1 month and 3 months were evaluated. We used two types of prostheses, i.e. PTFE and Titanium. Here we are reporting short term hearing results because long term success of stapes surgery is largely dependent on factors outside the control of surgeon like patient follow-up rate, period of study. The short-term results are a more accurate reflection of the actualsurgical outcome.

In the study, the hearing outcome was analysed by comparing the pre op airconduction and post op air conduction threshold and air-bone gap at 1 month and 3 months and analysis is done for PTFE and Titanium prostheses separately and determining if there was significant improvement. The average pre-operative and post-operative AC threshold was calculated by taking the frequencies across $500 \mathrm{~Hz}, 1000 \mathrm{~Hz}$ and $2000 \mathrm{~Hz}$. Air-bone gaps were calculated using air conduction and boneconduction thresholds at frequencies $500 \mathrm{~Hz}, 1000 \mathrm{~Hz}$ and 2000 $\mathrm{Hz}$.

The average pre-op hearing loss in this study with titanium was (AC) was $52.06 \mathrm{~dB} \pm 7.70$. The average post op hearing ( $\mathrm{AC}$ ) at 1 month follow up was $39.33 \mathrm{~dB} \pm 6.85$ with an average hearing gain of $12.73 \mathrm{~dB}$ which was significant. The average post op hearing (AC) at 3 months improved to $30.86 \mathrm{~dB} \pm 5.47$ with an average hearing gain of $21.2 \mathrm{~dB}$ which was also significant. This was similar to results of Boleas-Aquirre et al. [21] who reported the overall improvement in airconduction thresholds and pure-tone average air conduction for all frequencies after 1 year of surgery. Ataide et al. [20] did audiometric evaluation after stapedotomy with Fisch titanium prosthesis and showed improvement post operatively. The mean hearing gain was also reported by Boleas-Aquirre et al. [21].

In our study of 30 ears operated, based on improvement of $\mathrm{AB}$ gap (according to Wehr's Classification) among titanium prosthesis, 8 ears had excellent im- 
provement at 3 months post operatively, 1 ear had good improvement, 2 ears fair improvement and no failure cases by the end of 3 months post op. Singh et al. [21] found out that the titanium soft clip stapes piston gives good results in cases of stapedotomy forotosclerosis. The soft clip design is a new development in the evolution of stapespiston prostheses. Surgical introduction, placement, and fixation are easier than the earlier design of clip piston.

The air-bone gap with titanium in the study of Boleas-Aguirre et al. [21] was significantly reduced 1 year after surgery and remained so at 4 years. Preoperative air-bonegap, $34.04 \mathrm{~dB}$; at 1 year, $16.40 \mathrm{~dB}$; at 4 years, $17.3 \mathrm{~dB}$. In our study, the average pre op $A B G$ with titanium was $28.67 \mathrm{~dB} \pm 4.60$. The average post op ABG was analysed at 1 month and post op follow up showed AB gap of $17.21 \mathrm{~dB}$ \pm 7.37 with an average closure of $11.46 \mathrm{~dB}$ which was found to be significant. The average post op $\mathrm{ABG}$ at 3 months post op follow up was $12.36 \mathrm{~dB} \pm 5.29$ with an average closure of $16.31 \mathrm{~dB}$ which was found to be significant. Ataide et al. [22] found out that the mean low-frequency postoperative air-bone gap was $12.9 \mathrm{~dB}$. Twenty-five (75.8\%) patients had air-bone gaps of $10 \mathrm{~dB}$ and under; 32 (96.9\%) patients had gaps of $20 \mathrm{~dB}$ and under; and all patients had gaps of $30 \mathrm{~dB}$ and under.

The average pre-op hearing loss with PTFE was (AC) was $53.31 \mathrm{~dB} \pm 7.71$. The average post op hearing (AC) at 1month follow up was $41.75 \mathrm{~dB} \pm 7.53$ with an average hearing gain of $11.56 \mathrm{~dB}$ which was significant. The average post op hearing (AC) at 3 months improved to $34.12 \mathrm{~dB} \pm 8.95$ with an average hearing gain of $19.19 \mathrm{~dB}$ which was also significant. Ahmed et al. [23] assessed hearing improvement after stapedotomy for otosclerosis using PTFE loop prosthesis. Pre-operative audiograms showed conductive deafness. Carhart's notch was present in $33.3 \%$ cases. Tympanogram revealed loss of stapedial reflex. Postoperatively good hearing improvement was seen in $56.7 \%$.

In our study of 30 ears operated, 12 ears had excellent improvement at 3 months post operatively, 4 ears had good improvement, 1 ear fair improvement and 2 failure cases by the end of 3 months post op. In the study conducted by Ahmed et al. [24], postoperatively good hearing improvement was seen in $56.7 \%$, fair improvement in $30 \%$ and poor results in $10 \%$ cases. One patient developed dead ear.

The average pre op ABG with PTFE prosthesis was $29.26 \mathrm{~dB} \pm 8.73$. The average post op $A B G$ at 1 month post op follow up was $18.26 \mathrm{~dB} \pm 7.14$ with an average closure of $11 \mathrm{~dB}$ which was found to be significant. The average post op $\mathrm{ABG}$ at 3 months post op follow up was $14.2 \mathrm{~dB} \pm 8.62$ with an average closure of $15.06 \mathrm{~dB}$ which was found to be significant. Dall'igna et al. [25] in his study found out that bone-air gap reduced in an average value of $21.90 \mathrm{~dB}(\mathrm{p}<0.05)$ after the surgery in the group that received the PTFE prosthesis and gain in SRT was of 22.33 and the air-bone gap was below $20 \mathrm{~dB}$ in $80.6 \%$

All patients in the study had better improvement at 3 months post op when compared to 1 month post op air conduction and air-bone gap closure except in 
one case where there was displacement of prosthesis 3 months after stapes surgery and was operated again. Hearing improves once the swelling subsides, the slight bleeding behind the ear drum dries up and the packing is absorbed or removed, usually within two weeks. Hearing continues to get better over the next three months.

There was improvement in bone conduction in 27 out of 30 ears in the study after undergoing stapes surgery. Improvement was more in patients whose bone conduction preoperatively was equal to or more than $30 \mathrm{~dB}$. This is similar to studies of Morshed et al. [26] where he found out there was significant improvement of AC obtained after stapedectomy. There was also significant improvement of $\mathrm{BC}$ at all the frequencies examined of $6-12 \mathrm{~dB}$ and it depended on $\mathrm{BC}$ threshold before surgery. In the group of 37 patients with $\mathrm{BC}$ threshold before surgery $>$ or $=30 \mathrm{~dB}$, a significant improvement of BC after stapedectomy developed. In the group of 14 patients with $B C$ threshold before surgery $<30 \mathrm{~dB}$, the change of BC after stapedectomy was not significant. Successful stapedectomy improves bone conduction. It means that inpatients with otosclerosis, there is a reversible $\mathrm{BC}$ pseudo hearing loss and it is related to $\mathrm{BC}$ threshold before the operation.

Out of 30 ears (28 patients), 2 patients underwent bilateral surgery for otosclerosis. The typical age of onset of noticeable hearing loss is in the third decade of life, and hearing loss is bilateral in $70 \%$ of cases [18].

1 ear out of 30 ears (total of 28 patients where two patients underwent bilateral surgery) underwent revision surgery 3 months after primary surgery with PTFE prosthesis due to dislocation of prosthesis. The pre op air conduction threshold was $53.3 \mathrm{~dB}$. It improved to $48.3 \mathrm{~dB} 1$ month after surgery. But the hearing decreased 3 months after surgery to $60 \mathrm{~dB}$. The air bone gap pre operatively was $21.7 \mathrm{~dB}$. It improved to $\mathrm{ABG}$ of $20.3 \mathrm{~dB} 1$ month after surgery. The ABG became $36.7 \mathrm{~dB} 3$ months after surgery. This was due to dislocation of PTFE prosthesis. Skrivan et al. [27] reported the reasons of the recurrent or persisting hearing loss after previous stapessurgery indicated for otosclerosis. The main reason of the failed surgery was adhesions and dislocation of the prosthesis. The mean postoperative air-bone gap was $12.0 \mathrm{~dB}$. A mean postoperative air-bone gap closure within $10 \mathrm{~dB}$ occurred in 24 cases (55.8\%), between $11-20$ $\mathrm{dB}$ occurred in 11 cases (25.6\%) and above $20 \mathrm{~dB}$ in 8 cases (18.6\%).

On comparing hearing outcome with PTFE and titanium, $72.72 \%$ of ears (8 out of 11) with titanium prosthesis had excellent improvement in ABG at 3 months after surgery. There were zero cases with $A B G$ more than $31 \mathrm{~dB}$ whereas $63.16 \%$ of ears (12 out of 19) with PTFE prosthesis had excellent improvement in $A B G$ at 3 months after surgery whereas ABG more than $31 \mathrm{~dB}$ was seen in $10.52 \%$ cases ( 2 out of 19 ). So, $84.21 \%$ ears with PTFE attained ABG less than 20 $\mathrm{dB}$; it was $81.81 \%$ ears with titanium who attained ABG less than $20 \mathrm{~dB}$. Thus it can be concluded that the result with respect to ABG between the two prosthesis were comparable and produced similar results. Similar results were seen with 
studies conducted by Massey et al. [28] where the study group was comprised of 35 titanium and 183 PTFE prostheses. Closure of the air-bone gap to less than 20 $\mathrm{dB}$ was achieved in $86 \%$ of the ears with PTFE prosthesis compared with $71 \%$ of those with titanium prostheses. Other studies included were by Rajesh et al. [29] where postoperative ABG of $20 \mathrm{~dB}$ or less was seen in $96 \%$ in both groups.

The average AC threshold post op at 1 month using PTFE was $41.75 \pm 7.53$. The average AC threshold post op at 1 month using titanium was $39.33 \pm 6.85$. The comparative study was not statistically significant. The average AC threshold post opat 3 month using PTFE was $34.12 \pm 8.95$. The average AC threshold post op at 3 month using titanium was $30.86 \pm 5.47$. The comparative study was also not statistically significant.

The average ABG threshold post op at 1 month using PTFE was 18.26 \pm 17.14. The average ABG threshold post op at 1 month using titanium was $17.21 \pm 7.37$. The comparative study was not statistically significant. The average ABG threshold post op at 3 month using PTFE was $14.2 \pm 8.62$ which was not statistically significant. The average ABG threshold post op at 3 month using titanium was $12.36 \pm 5.29$ which was also not statistically significant. This was similar to studies of Rajesh et al. [29] where the mean postoperative ABG was $8.2 \mathrm{~dB}$ and 11.5 $\mathrm{dB}$ for PTFE and Titanium group respectively.

\subsection{Alternative Treatment}

\subsubsection{Hearing Aids}

All patients with conductive hearing loss caused by otosclerosis may use hearing aids as an alternative to surgery. If the patient has a significant sensorineural component to the hearing loss, a hearing aid may be required even after successful stapedectomy. A patient with far advanced otosclerosis requires a hearing aid at all times. It may take 4 months before these patients can tolerate and benefit from the hearing aid.

\subsubsection{Fluoride Therapy}

Injury to the inner ear is believed to occur as a result of the spread of proteolytic enzymes to the inner ear fluids from an active otospongiotic focus, with resultant injury to the organ of Corti and spiral ligament [30]. In patients with evidence of progressive sensorineural hearing loss, fluoride therapy has been shown to reduce the progression of hearing loss due to the conversion of the active otospongiotic lesion to a more stable otosclerotic lesion [30]. Patients are typically treated with Florical $8 \mathrm{mg}$ three times per day until hearing loss stabilizes.

\section{Conclusions}

The main objective of this study is to assess the hearing outcome in stapessurgery using PTFE and titanium prostheses at 1 month and 3-month post operatively. The post operative $\mathrm{AC}$ threshold gain and $\mathrm{ABG}$ were taken as the two variables used to determine the hearing outcomes. The AC threshold improved post operatively in $95 \%$ ears with PTFE and 100\% ears with titanium. The main 
cause for failure is dislocation of prosthesis which was encountered in one of the ears in the study with PTFE. The ABG attained post operatively at 3 months to less than $20 \mathrm{~dB}$ was in $84.21 \%$ ears of PTFE and $81.81 \%$ ears of titanium.

The bone conduction improved post operatively in $90 \%$ of ears which was more with ears with pre-op bone conduction threshold more than or equal to 30 $\mathrm{dB}$. The comparison of hearing outcome in stapes surgery using PTFE and titanium were not significant statistically. Both prostheses produced similar and comparable results and it cannot be concluded one prosthesis is better than the other since ours is a small case series and the study is for shorter duration of time. It may require a larger case series and longer duration of time to find out if there is significant difference between the two prostheses. So PTFE and titanium can be equally suggested for patients in stapes surgery. In our study, we have analysed the hearing outcomes in stapes surgery using PTFE and titanium prostheses. Hence it is concluded that stapes surgery can be effectively used to improve hearing in otosclerosis irrespective of the prosthesis used.

\section{Conflicts of Interest}

The authors declare no conflicts of interest regarding the publication of this paper.

\section{References}

[1] Toynbee, J. (1860) Diseases of the Ear. Blanchard \& Lea, Philadelphia.

[2] Mudry, A. (2006) Adam Politzer (1835-1920) and the Description of Otosclerosis. Otology \& Neurotology, 27, 276-281. https://doi.org/10.1097/01.mao.0000187050.04286.80

[3] Ruedi, L. (1968) Friedrich Siebenmann: 1852-1928. Archives of Otolaryngology, 88, 213-217. https://doi.org/10.1001/archotol.1968.00770010215027

[4] House, J.W., Sheehy, J.L. and Antunez, J.C. (1980) Stapedectomy in Children. Laryngoscope, 90, 1804-1809. https://doi.org/10.1288/00005537-198011000-00007

[5] Altmann, F., Glasgold, A. and Macduff, J.P. (1967) The Incidence of Otosclerosis as Related Torace and Sex. Annals of Otology, Rhinology \& Laryngology, 76, 377-392. https://doi.org/10.1177/000348946707600207

[6] Friedmann, I. (1974) Pathology of the Ear. Blackwell Scientific Publications, Oxford.

[7] Guild, S.R. (1944) Histologic Otosclerosis. Annals of Otology, Rhinology \& Laryngology, 53, 246.

[8] Levin, G., Fabian, P. and Stahle, J. (1988) Incidence of Otosclerosis. American Journal of Otolaryngology, 9, 299-301.

[9] Nager, G.T. (1969) Histopathology of Otosclerosis. Archives of Otolaryngology, 89, 341-363. https://doi.org/10.1001/archotol.1969.00770020343022

[10] Schuknecht, H.F. (1966) Sensorineural Deafness in Otosclerosis. Annals of Otology, Rhinology \& Laryngology, 75, 418. https://doi.org/10.1177/000348946607500211

[11] Tato, J.M. and Tato Jr., J.M. (1967) Otosclerosis and Races. Annals of Otology, Rhinology \& Laryngology, 76, 1018-1025. https://doi.org/10.1177/000348946707600512 
[12] Berliner, K.I. and House, W.F. (1982) The Cochlear Implant Program: An Overview. Annals of Otology, Rhinology \& Laryngology, 91, 11-14.

[13] Otosclerosis. Tampa Bay Hearing. https://www.tampabayhearing.com/ear-education/auditory-education/otosclerosis/

[14] Goycoolea, M.V. (1991) Otosclerosis. Otology and Neuro-Otology, 237, 1489-1491.

[15] Kulakova, L.A., Poliakova, E.P., Bodrova, I.V. and Lopatin, A.S. (2014) The Results of the Surgical Treatment of Otosclerosis in the Elderly Subjects. Vestnik Otorinolaringologii, 3, 17-19.

[16] Massey, B.L., Hillman, T.A. and Shelton, C. (2006) Stapedectomy in Congenital Stapes Fixation: Are Hearing Outcomes Poorer? Otolaryngology-Head and Neck Surgery, 134, 816-818. https://doi.org/10.1016/j.otohns.2005.10.063

[17] Shiao, A.S., Kuo, C.L., Cheng, H.L., Wang, M.C. and Chu, C.H. (2014) Controversial Issues of Optimal Surgical Timing and Patient Selection in the Treatment Planning of Otosclerosis. European Archives of Oto-Rhino-Laryngology, 271, 1007-1014. https://doi.org/10.1007/s00405-013-2529-6

[18] House, J.W. and Cunningham, C.D. III (2010) Otosclerosis. Cummings Otolaryngology Head and Neck Surgery. Fifth Edition, 144.

[19] Shabana, Y.K., Ghonim, M.R. and Pedersen, C.B. (1999) Stapedotomy: Does Prosthesis Diameter Affect Outcome? Clinical Otolaryngology and Allied Sciences, 24, 91-94. https://doi.org/10.1046/j.1365-2273.1999.00207.x

[20] Portmann, D., Alcantara, M. and Vianna, M. (2007) The Length of the Piston in Otosclerosis Surgery. Revue de Laryngologie-Otologie-Rhinologie, 128, 55-58.

[21] Boleas-Aguirre, M.S., Ruiz de Erenchun-Lasa, I. and Bulnes-Plano, M.D. (2015) Audiological Results after Total Ossicular Reconstruction for Stapes Fixation. European Archives of Oto-Rhino-Laryngology, 272, 3123-3130. https://doi.org/10.1007/s00405-014-3303-0

[22] Ataide, A.L., Bichinho, G.L. and Patruni, T.M. (2013) Audiometric Evaluation after Stapedotomy with Fisch Titanium Prosthesis. Brazilian Journal of Otorhinolaryngology, 79, 325-335. https://doi.org/10.5935/1808-8694.20130058

[23] Singh, P.P. and Goyal, A. (2013) Our Experience with the Titanium Soft Clip Piston Stapedotomy. Indian Journal of Otolaryngology and Head \& Neck Surgery, 65, 280-282. https://doi.org/10.1007/s12070-011-0459-4

[24] Ahmed, S., Raza, N., Ali, L., Ullah, S. and Iqbal, S. (2006) Hearing Improvement after Stapedotomy Using Teflon Loop Prosthesis. Journal of College of Physicians and Surgeons Pakistan, 16, 659-661.

[25] Dall'igna, C., Teixeira, V.N., Dall'igna, D.P. and Rosito, L.P. (2008) Results of Stapes Surgery Forotosclerosis with Two Kinds of Prosthesis in Residency Training. Brazilian Journal of Otorhinolaryngology, 74, 826-832. https://doi.org/10.1590/S0034-72992008000600004

[26] Morshed, K., Siwiec, H., Szymański, M. and Gołabek, W. (2003) Bone and Air Conduction after Stapedectomy. Annales Universitatis Mariae Curie-Sklodowska, 58, 33-37.

[27] Skrivan, J., Cada, Z., Kluh, J., Boucek, J., Profant, O. and Betka, J. (2014) Revision Operations after Previous Stapes Surgery for Persisting Hearing Loss. Bratislavske Lekarske Listy, 115, 442-444.

[28] Massey, B.L., Kennedy, R.J. and Shelton, C. (2005) Stapedectomy Outcomes: Titanium versus Teflon Wire Prosthesis. Laryngoscope, 115, 249-252.

https://doi.org/10.1097/01.mlg.0000154727.85539.76 
[29] Vishwakarma, R., Patadia, S., Goswami, P., Patel, K. and Darji, D. (2014) Teflon vs. Titanium Prostheses in Stapes Surgery. Journal of Otolaryngology, 4, 53-63.

[30] Causse, J.R., Causse, J.B., Uriel, J., Berges, J., Shambaugh, G.E. and Bretlau, P. (1993) Sodium Fluoride Therapy. American Journal of Otolaryngology, 14, 482-490. 